\title{
Masculinity, Organizational Culture, Media Framing and Sexual Violence in the Military
}

\author{
Steven Kuhl ${ }^{1}$, Anna E. Kosloski ${ }^{1}$, Stephanie Bontrager Ryon ${ }^{2, *}$ and Astrid Monar ${ }^{1}$ \\ 1 School of Public Affairs, University of Colorado, 1420 Austin Bluffs Parkway, Colorado Springs, CO 80918, \\ USA; skuhl@uccs.edu (S.K.); akoslosk@uccs.edu (A.E.K.); amonar@uccs.edu (A.M.) \\ 2 Department of Criminal Justice, Tarleton State University, 1333 W Washington St, \\ Stephenville, TX 76402, USA \\ * Correspondence: sryon@uccs.edu; Tel.: +1-(850)-212-0675
}

Received: 28 December 2017; Accepted: 25 April 2018; Published: 15 May 2018

\begin{abstract}
Sexual violence in the military is woven into history, with stories and myths that date back to the times of ancient Rome. For example, military conquests thousands of years ago involved looting, pillaging, and raping - the "spoils of war" for the winning side. Over time, women, seen as sexual outlets, continued to be used to boost soldier morale in combat. Today, instances such as the Marine sexual misconduct scandal are still associated with notions of male empowerment through victimization of enlisted and civilian women, despite female officers making up $14 \%$ of service members across all military branches. To determine if the optics of violent and predatory behavior within the military has changed from the "spoils of war", the current study utilized qualitative content analysis to analyze the media frames of military sexual assault and sexual harassment over the past 20 years. Through holistic reflection, the inquiry explores military framing by the media during high-profile incidents of misconduct from 1996 to 2013. The Aberdeen Proving Ground, Lackland Airforce Base, and Airforce Academy sexual assault cases demonstrate that responsibility and human-interest frames are the most prominent optics used by the media to describe these events. Further, since the first case in 1996, media coverage of sexual harassment and assault within the military has declined significantly. This suggest that, while media framing may accurately reflect these offenses, these offenses are considered less and less news worthy.
\end{abstract}

Keywords: sexual assault; military; media; framing; armed forces; sex crimes; harassment

\section{Introduction}

Sexual violence is broadly defined by scholars to include rape, sexual assault, sexual aggression, and sexual harassment (Castro et al. 2015; Sexual Violence 2017; Zaleski 2016; Jozkowski 2015). Sexual assault occurs within the U.S. Military affecting the lives of 9-13 percent of servicewomen and one to two percent of servicemen, annually (Holland et al. 2014). According to Holland and colleagues, these estimates are significantly under-reported (Holland et al. 2014). The military has been working to reduce sexual violence since the highly publicized Aberdeen Proving Ground case in 1996. Allegations at Aberdeen included wide spread sexual harassment and drill sergeants sexually assaulting female trainees (Rosen and Martin 1998). Most recently, the "Marines United" scandal made national news in 2017 when male Marines used Facebook to post sexually explicit photographs of female Marines (USA Today 2017). With more than 30,000 members, the Facebook page included harassing, abusive, and degrading messages about females. Posts also explicitly suggested sexual assault against some of the women in the pictures (USA Today 2017). Eleven years apart, these cases demonstrate that the Armed Forces are still actively dealing with sexual violence, and are doing so under media scrutiny. 
Media connect people to socially shared realms of understanding through magazines, newspapers, radio, television, and films (Chesebro 1984). In keeping with their role in social understanding, media outlets cover cases of sexual violence within the Armed Forces. Media serve multiple functions in this capacity by documenting allegations, investigating findings, and publicizing how the military addresses these problems. This reporting records events, but equally important, also determines the optics or frames used to present and interpret information for the public (Neuman et al. 1992). In the latter role, the media play an essential role in determining how the public processes sexual violence in the military and potentially how the Armed Forces respond to these cases (Semetko and Valkenburg 2000).

Military sexual violence is defined as sexual assault against or by anyone who is subject to Article 120 of the Uniform Code of Military Justice (UCMJ), as directed from Title 10, United States Code-Section 920 (Government, 10 U.S. Code § 920-Art. 120, 2011). The Manual for Courts-Martial (2012) defines rape as "committing a sexual act upon another person with the unlawful use of force which causes or is likely to cause bodily harm, threatens to cause grievous bodily harm, death, or kidnapping; rendering a person unconscious or giving said person a drug either through force, threat of force, or without their knowledge which would significantly impair the ability of a person to control their conduct" (pp. IV-68). Further, sexual assault includes "making a false claim that they serve a professional purpose; makes them believe that they are someone else; commits a sexual act against someone that is asleep, unconscious or incapable to give consent to the act due to impairment of drugs or alcohol, or has a mental or physical limiting disease, defect, or condition that is known or reasonably known by the person" (pp. IV-68). While criminal definitions within the military are clear, they do not address social norms and values such as rape culture or hyper-masculinities that potentially drive sexual violence.

Rape culture is permissive of actions, thoughts, and words that are, or seem as though, sexual assault and sexual harassment is acceptable (Nicoletti et al. 2009). Further discussion around rape culture includes normalizing sexual aggression, victim blaming, and the acceptance of rape myths (Zaleski et al. 2016). Scholars have documented the prevalence of rape culture in media from video games (Anderson and Bushman 2000), advertisements (Capella et al. 2013), social media (Zaleski et al. 2016) and print news (Franiuk et al. 2008). Rape culture is not only present in forms of media but can also exist within institutions and organizations and has been documented within military culture (Castro et al. 2015; Cheney et al. 2014; Kasinsky 1998; Lohman 2015).

Violence is a necessity in the military and is actively promoted as a defining cultural feature (Wilds 1999). Gender norms within the military have historically designated female members to specific non-combat positions. In tandem, these aspects of military norms promote male violence and female passivity by dividing troops, missions, and assignments along gender lines. Supporting the gender divide are arguments about the suitability of women in combat roles because of their assumed negative impact on male soldiers and their ability to function effectively in the presence of women (Dean 1994). Others suggest that, in high stress, inherently aggressive situations, men cannot control their sexual urges, and their degrading views on women in the military (Dean 1994; McKeon 2013; Neill 2000). Finally, a leading perspective on sexual assault in the military asserts that improvements in military roles for women have resulted in stronger expressions of hyper-masculine values. These are characterized by, "competitiveness, physical strength, heavy alcohol use, violence, risk-taking, and the denigration and sexual objectification of women" (Weitz 2015, p. 165). As the Department of Defense (DoD) tries to combat the hyper-masculine gender norms and respond directly to incidents of sexual assault, the public has followed the stories covered within the media. Media coverage of military sexual assault began in the early 1990s and continues today. These print, audio, and digital narratives are important to the military because their framing has consequences for consumers' perception of sexual violence in the Armed Forces (Semetko and Valkenburg 2000). However, the way in which the media frames sexual 
violence in the military has received minimal focus by scholars ${ }^{1}$. Uniquely addressing this issue through content analysis, this study examined masculinities, organizational culture, and media framing for the Aberdeen Proving Ground, the U.S. Air Force Academy, and the Lackland Air Force Base sexual assault incidents between 1996 and 2013. Focusing on media framing, the first research question addressed the most frequently used optics in news coverage of these events. Additionally, the analysis included an assessment of the prevalence of media narratives concerning sexual violence in the military.

\section{Theoretical Context}

\subsection{Masculinities}

When people are young, they learn how to "do" gender by absorbing the social schemas that define masculinity and femininity (Carlsson 2013). Social schemas are representations of the patterns seen in past social interactions that guide people in their understanding of social cues during future interactions. They are also ideas and practices that people rely on when making decisions (Simons and Burt 2011). Whatever social circles they are a part of when they are growing up make an impression on how they "do" gender as adults. Generally, "doing masculinity" is defined as the opposite of femininity. "Doing masculinity", a phrase developed by Messerschmidt (Messerschmidt 1993), is synonymous with being strong, independent, ambitious, dominating, self-controlled, using violence for defense, being rational, and even including sexual conquests. The criminal aspect of "doing masculinity" is when a person takes the concepts they have learned about it and apply it in a deviant manner. It is not uncommon that the traits of domination and aggression- "doing masculinity" — cause some to equate sexual prowess with assault (Carlsson 2013). Media influence can either frame "doing masculinity" as acceptable or not, and in turn, shapes the public's perception of sexism, misogyny and sexual violence.

Understanding the concept of masculinity plays an important role in understanding how the media portrays the hyper-masculine culture of the military. Violence in the military has been associated with hyper-masculinity as seen in some media reports of war (Ryan 2004). Understanding how the media portray the hyper-masculinity of the military allows people the ability to understand how it can foster men who commit sexual assault and sexual harassment. The media, through framing, has portrayed the military as a hyper-masculine organization where rape myths and rape culture are acceptable (Kasinsky 1998). News stories like these can influence the way the public thinks about the military, and how those who join believe they should act. These beliefs can come from different cultures that make up the organizational culture of the military.

\subsection{Organizational Culture}

Organizational Culture describes how societal order is based entirely on the interactions and conformity of an individual in the context of a larger culture. The frames that the media use have been shown to influence organization culture and the judgments and actions that those within the organizations take (Semetko and Valkenburg 2000). There are several categories of culture that individuals can participate in: macrocultures, organizational cultures, subcultures, and microcultures (Schein 1990, 2010). The different levels of culture are influenced by media framing which can have an impact on how those cultures operate. Macrocultures are those that are on a national sized scale. Organizational cultures are large organizations, such as the private sector professions and the government or public sectors. Subcultures are those cultures that are on a slightly smaller scale such as nurses, doctors, and law enforcement. Microcultures are the smallest of the cultures which are within subcultures such as peer groups within certain professions (Schein 2010).

1 Exceptions include Kasinsky (1998) who studied the Tailhook sexual assault scandal and analyzed how media framed the case from the first national report to the aftereffects, including Congressional response. Findings from the study indicated gender norms such as the "boys will be boys" rhetoric were highly reinforced among media coverage of the incident (Kasinsky 1998). 
People are generally a part of multiple cultures. Being a part of multiple cultures can cause differentiation when there is conflict between those cultures, which can then skew the way that an individual views the organization (Taylor et al. 2006). When a person joins the military, they are still a part of the cultures they identified with before they joined. The cultures can vary through the different categories and include ethnic, religious, political, professional, private, familial, and any others. Individuals bring values, from their other cultures, with them into the military (Denison and Mishra 1995). All cultures that people are a part of make-up who they are and how they interact within society.

Sexual assault incidents in the military possibly continue because in organizational cultures that have hyper-masculine norms as part of their primary mission, it is difficult to differentiate between those who subscribe to the positive aspects of masculinity and those who use those values to justify sexual violence. Katz (1995) discussed how many theorists have argued that cultures within the United States encourage many attitudes and behaviors that enforce sex-role assignments. Masculinity is one of the sex-role assignments and includes violence against women, which is primarily a learned behavior (Schein 1990; Katz 1995). The identification of men who bring deviant values into the military organizational culture is also difficult. Especially when the concept of rape culture and rape myths are believed by many within the military and is reinforced by media framing of sexual violence (Kasinsky 1998).

\subsection{Media Framing}

Media frames, as suggested by Entman (1993), “ . . select relevant aspects of the studied writings, makes them more salient, and allows for the identification of problem definitions, an interpretation of causes, moral evaluation, and recommendations for actions or treatment of the problem" (Entman 1993, p. 57). Entman (1993) described the significance of framing as it pertains to salience or the power of communicating content. Framing as a mechanism of analysis has been well-documented (Semetko and Valkenburg 2000; Entman 1993; Matthes and Kohring 2008). As described by Neuman, Just and Crigler (Neuman et al. 1992, p. 60), frames are "conceptual tools which media and individuals rely on to convey, interpret, and evaluate information". These optics set the stage for how the public interprets and understands events. The reality of what those who are influenced believe, is framed in such a way as to "promote a particular problem definition, causal interpretation, moral evaluation, and/or treatment recommendation" (Entman 1993, p. 53). Frames help readers in their ability to visualize, understand, and interpret information that is available to them.

Some examples of media frames are: human-interest frames (Semetko and Valkenburg 2000), personal frames (Entman 1993), and the social science frame (Bing and Lombardo 1997). Semetko and Valkenburg (2000, p. 95) identified the human-interest frame as "bringing a human face or an emotional angle to the presentation of an event, issue, or problem." Neuman et al. (1992) also discussed this frame as having a human impact on the public and is one of the more common frames in the news media. Personal frames, as discussed by Entman (1993), revolve around how the media makes personal issues salient to the public in ways that encourage empathy. Bing and Lombardo (1997) presented the social science frame as a common occurrence in print media that is focused on an objective reader. The writers who use this frame tend to remain outside the specifics of particular cases and explore the issues at hand in a more general and abstract approach (Bing and Lombardo 1997).

Researchers have used framing to examine how media portrays social phenomena for a wide range of issues. For example, Semetko and Valkenburg (2000) used media frames to analyze newspaper and television news stories to assess the way media delivered information on political figures. In addition, Ryan (Ryan 2004) used framing to identify how the media portrayed acts of terrorism and how the government responded. Both Semetko and Valkenburg (2000) and Ryan (2004) found that frames have been shown to influence public perception of the topics studied. The framing effects are "changes in judgement engendered by subtle alterations put in the definition of judgment or choice of problems" (Iyengar 1987, p. 816). 
Military sexual violence includes many aspects of sexual misconduct. In some cases, extreme violence is used, while, in other cases, it is not, but they are all sexual crimes that are sometimes defended by those who believe in rape myths and live within the rape culture (Bing and Lombardo 1997). Organizations that are influenced by social schemas, which define what masculinity is supposed to be, regarding sexuality and crime, have difficulty dealing with sexual violence. The way the media frames the news coverage about military sexual assault plays a role in how the civilian and military populations think about it and respond. This can bring awareness to the many programs, systems, ideas, and research studies and can assist in the reduction, and ultimately elimination, of sexual assault in the military. For this reason, this study set out to explore the frames used in media coverage of three cases of pervasive military sexual violence.

\section{Data and Methods}

\subsection{Data Collection Process}

Qualitative research has been used extensively by scholars to understand social phenomena, especially in the absence or unavailability of quantitative information (Esterberg 2002). For this study, data consisted of Lexis Nexis, print news stories that were retrieved from two major newspaper outlets: The New York Times and USA Today. These two outlets were selected because they were among the top five newspapers, according to distribution numbers obtained from the Alliance for Audited Media (News Media 2017). Additionally, both news outlets covered each of the sexual assault incidents within the time parameters set for this study. The following search terms were utilized for data collection process: "Aberdeen Proving Ground", "Lackland Air Force Base", "United States Air Force Academy", and "sexual assault". The time span ranged from 1996 to 2013 to account for as much news coverage of the incidents as possible, including coverage from the time of the incident to the conclusion of the event. This allowed researchers to explore media frame changes over time.

\subsection{Sample}

Using the established search terms, data collection initially resulted in a total of 270 articles in The New York Times and USA Today. This included 115 articles about the Aberdeen Proving Ground sexual assault scandal, 131 articles about the U.S. Air Force Academy sexual assault scandal, and 24 articles about the Lackland Air Force Base sexual assault scandal. After reviewing these articles, it was determined that only some were relevant to the cases. The articles that were irrelevant had little to no information on the allegations or only mentioned the name of the scandal in regards to other, unrelated news stories. To ensure reliability, a second researcher independently reviewed every article from each of the three military incidents and recorded relevant versus non-relevant articles. The primary researcher then compared articles and determined the final list of relevant articles utilized in the study. The final sample $(n=130)$ resulted in 72 Aberdeen Proving Ground articles, 47 articles on the U.S. Air Force Academy sexual assault scandal, and 11 relevant articles about the Lackland Air Force Base scandal.

\subsection{Case Descriptions}

Aberdeen Proving Ground Sexual Assault Scandal. The U.S. Army was in the spotlight in 1996, following allegations of sexual assault on female trainees by drill sergeants at Aberdeen Proving Grounds, Maryland. By November 1996, 34 female trainees reported being victims of multiple sex crimes. These sex crimes ranged from sexual harassment to rape. The female trainees reported that they were constantly sexually harassed which turned into sexual assaults that included forcible rape and sodomy over an extended period (Rosen and Martin 1998; Lohman 2015; West 1997).

Military investigators talked to over 9000 personnel, which consisted of both soldiers and civilian employees by either talking individually or participating in focus groups. The investigators also surveyed over 20,000 soldiers and discovered that three primary personnel were said to be perpetrating 
these sexual assaults, sexual harassments, and rapes. The Army investigators found evidence to charge three drill sergeants and a company commander with rape and obstruction of justice. The three soldiers were responsible for creating a climate that promoted rape, sexual assault, and sexual harassment (Lohman 2015; West 1997). These sexual assault incidents were the catalysts for the beginning of the Army's re-examination of policies that were in place that covered sexual assault and sexual harassment.

United States Air Force Academy Sexual Assault Scandal. The pattern of scandal continued approximately seven years later, at the United States Air Force Academy in Colorado Springs, Colorado. On 2 January 2003, an email was delivered to the Secretary of the Air Force, the Chief of Staff of the Air Force, Senator Wayne Allard, Senator Ben Nighthorse Campbell, and a variety of news media outlets. The email was sent by someone using the pseudonym "Renee Trindle". The email described a problem of rampant sexual assault within the United States Air Force Academy (Dalton 2004; Polk 2004).

During the investigation, there were 56 discovered cases of reported sexual assault that occurred during the period since 1993. Specifically, there were 31 allegations of rape, 18 allegations of indecent assault, four allegations of indecent offenses against children, two allegations of sodomy, and one allegation of attempted rape (Polk 2004). In surveys that were conducted over the time period, the investigators found that there were over 140 enlisted women who stated that they were sexually assaulted but were afraid to report because of reprisals from leadership and fear that they would be blamed for being sexually assaulted (Fowler 2003).

Lackland Air Force Base Sexual Assault Scandal. Air Force officials were alerted in June 2011 that basic military training instructors reported to investigators that they overheard other instructors discussing sexually related incidents. An investigation began, which opened up the door for multiple reports of sexual assault, harassment, and misconduct to be brought forward. Thirty-two basic training instructors were identified as allegedly committing some type of sexual offense and were tried in courts-martial. Of those, 29 were convicted. There were 59 victims, three of them men, who reported an offense.

The main theme throughout the investigation and the Senate Armed Services Committee hearing was that a change in culture was needed to address the sexual assault problem within the military. The change in culture covers many aspects. The aspects General Rice identified as needing change included the way in which training was conducted, personal accountability, leadership accountability, behavior modification within and outside the workplace, and excessive alcohol consumption (McKeon 2013). Additional changes in policy and procedure made by the DoD in regard to these issues may have been influenced by the media framing of this scandal.

\subsection{Analytical Strategy}

These data were analyzed through qualitative content analysis and descriptive statistics to examine how the media framed the military sexual assault scandals and which frames appeared most often throughout the period of coverage. Qualitative content analysis is a methodology used for the systematic description of the meaning within texts (Matthes and Kohring 2008; Flick 2014). This study adopted an existing measure used by Entman (1993) and Semetko and Valkenburg (2000) to examine media frames in text. Based on the work of Semetko and Valkenburg (2000), five frame categories were established: responsibility, human-interest, conflict, character, and action to assess coverage of the military sexual assault scandals. A brief description of each frame is provided below.

Human-Interest. This frame is used to elicit an empathetic, sympathetic, or compassionate response to the actors within the stories. It can bring out feelings of anger and outrage towards actors who have done something to another actor within the story. It covers the telling of people's individual stories related to the problem, to allow the reader to connect with them. Stories that emphasize how individuals and groups are affected by the issue cited in the article are in this category. In addition, any stories that veer away from the central issue and delves into the actors' personal and private lives are categorized here. This illustrates how people are affected by an issue and how their personal story can cause the reader to have a certain emotional response. 
Responsibility. This frame is used to identify who or what is responsible for a specific issue within a news story. This frame may identify an individual as perpetuating or causing an action to happen. The media uses this frame to suggest that an organization or level of government is responsible for a problem. The media even uses this frame to suggest that a level of government could take action against the problem.

Conflict. This frame is used to identify if the story refers to two or more sides within an issue. It uncovers any disagreements between parties that may be the focal point of the story. It also describes if there are any winners or losers within the story. The conflict frame can cover many aspects, including court testimony, where there are two different stories that are at odds. It can also include investigations where different witnesses are reporting the same instance but the stories do not corroborate. Any time that there are multiple aspects of the story that go against each other somehow, it is part of this framework.

Character. This frame focuses on an individual's character and their mental and moral qualities. It has been referred to as the "morality" frame because it refers to societal expectations of behavior. If someone is described as acting out of character, they may be conducting themselves inappropriately. If someone is acting in regard to the morals and values of their organization, or they are following the rules by doing things in accordance with policy and procedure, they may be acting appropriately.

Action. The final frame is all about remedies toward an issue, event, or suggested solutions towards an issue. Therefore, the frame includes what actions need to be taken immediately or what steps have already been taken. They also use this when an organization has already taken action to correct a problem and the news media wants to draw their readers' attention to the discussed remedy.

To measure the frames, three yes/no questions were utilized per category for a total of 15 questions assessed per news story. The yes (1) and no (2) answers were then entered into SPSS to determine percentages of responses for each media frame. The results shown in Table 1, allowed for the researcher to see which frame was more predominant within the news articles and which frame was more predominant throughout the time period of the sexual assault scandals (Semetko and Valkenburg 2000; Entman 1993). Articles could only have one dominate frame.

Table 1. Coding Inter-rater Reliability.

\begin{tabular}{|c|c|c|c|}
\hline Frames with Questions & $\begin{array}{c}\text { Aberdeen } \\
-1 \text { to } 1\end{array}$ & $\begin{array}{l}\text { USAFA } \\
-1 \text { to } 1\end{array}$ & $\begin{array}{l}\text { Lackland } \\
-1 \text { to } 1\end{array}$ \\
\hline \multicolumn{4}{|l|}{ 1. Human Interest } \\
\hline Does the story emphasize how individuals and groups are affected by the issue/problem? & 0.573 & 0.597 & 0.876 \\
\hline Does the story go into the private or personal lives of the actors? & 0.19 & 1.00 & 1.00 \\
\hline Does the story suggest that some level of government is responsible for the issue/problem? & 0.634 & 0.505 & 0.150 \\
\hline Does the story suggest that an individual or group of people in society is responsible to the issue/problem? & 0.525 & 0.595 & 0.717 \\
\hline Does the story suggest that some level of government has the ability to alleviate the problem? & 0.544 & 0.549 & 0.866 \\
\hline \multicolumn{4}{|l|}{ 3. Conflict } \\
\hline Does the story refer to two sides or more? & 0.268 & 1.00 & 1.00 \\
\hline Does the story reflect disagreement between parties? & 0.528 & 0.651 & 0.723 \\
\hline Does the story describe winners and losers? & 0.468 & 1.00 & 1.00 \\
\hline \multicolumn{4}{|l|}{ 4. Character } \\
\hline Does the story offer special social prescriptions about how to behave? & 0.298 & 0.657 & 0.764 \\
\hline Does the story suggest that a party/parties acted appropriately? & 0.274 & 0.466 & 1.00 \\
\hline Does the story suggest that a party/parties acted inappropriately? & 0.526 & 0.695 & 1.00 \\
\hline \multicolumn{4}{|l|}{ 5. Action } \\
\hline Does the story suggest that the problem requires an urgent immediate action? & 0.511 & 0.484 & 1.00 \\
\hline Does the story suggest actions that should be taken? & 0.511 & 0.746 & 0.717 \\
\hline Does the study suggest that there was an action applied as a response to the problem? & 0.648 & 0.510 & 0.866 \\
\hline
\end{tabular}


Content analysis is a methodology that is flexible based on the data and information collected. For instance, content analysis can use inductive or deductive approaches to exploring phenomena (Esterberg 2002; Hsieh and Shannon 2005). Second, content analysis can reduce the amount of material the researcher works with by focusing on certain aspects of meaning related to the overall research question. This study utilized a deductive approach by exploring the presence of existing frames within these data. A final component of qualitative content analysis is that the methodology involves a systematic approach or a series of steps regardless of the types of data (Flick 2014; Hsieh and Shannon 2005). In this study, these data were first evaluated to see the relevancy to the research question. Then the coding frames were explored through focused coding of the yes/no questions. Inter-reliability was compared and analysis looked at frequencies of the frames (Entman 1993; Matthes and Kohring 2008).

Inter-coder reliability is important because it explains how stable the coding of one researcher is compared to another when the relevant material, frames, and questions are selected (Semetko and Valkenburg 2000; Kohlbacher 2006; Iyengar and Simon 1993). This study checked for reliability by having a second researcher engage in focused coding. The primary researcher was then able to compare the coders' results. Cohen's Kappa was then assessed in SPSS to determine the rate of which these data were captured by the measures, versus agreement due to chance. This technique was appropriate because these data were nominal (yes/no) and coded by two independent raters who reviewed the exact same data files for all observations.

While scholars vary on a definitive standard of what constitutes satisfactory levels of agreement, Cohen (1960) suggested the Kappa result be interpreted as the following: values $\leq 0$ represent no agreement, $0.01-0.20$ as none to slight, $0.21-0.40$ a fair amount of agreement, $0.41-0.60$ moderate agreement, $0.61-0.80$ substantial agreement, and $0.81-1.00$ almost perfect agreement. The majority of coded frames fell in the moderate to near perfect agreement ranges (coder ratings available upon request).

Descriptive statistics were utilized to determine how many times the media frames were present during the each scandal and which frame was most predominant. Total counts for the "yes" answers to the frame questions are provided to determine the prevalence of the frames. Data from both coders were compared and the numbers recorded reflect the numbers that the coders both indicated "yes" answers to the questions within each of the five frames. The coding for each of the five frames were compared. Those that had two or more "yes" answers within the frame from both coders, were counted as a strong indicator of a specific frame being the correct one.

\section{Results, Discussion, and Limitations}

\subsection{Results}

Research Question 1: Which optics were used to frame the sexual assault cases within the media?

Qualitative analysis indicated the prevalence of media frames in these data. A strong presence of the specific media frame was indicated by two or more questions coded as "yes". The Aberdeen Proving Ground scandal articles showed that the media had a strong presence of the human-interest frame six times; the responsibility frame 30 times; the conflict frame two times; the character frame three times; and the action frame eight times. The United States Air Force Academy scandal articles showed that the media had a strong presence of the human-interest frame six times; the responsibility frame 26 times; none in conflict frame; none in the character frame; and the action frame 10 times. The Lackland Air Force Base scandal showed that the news media presented a strong usage of the human-interest frame four times; the responsibility frame three times; the conflict frame two times; the character frame one time; and the action frame one time. Figure 1 shows the proportion of time each frame used during each of the sexual assault scandals. 


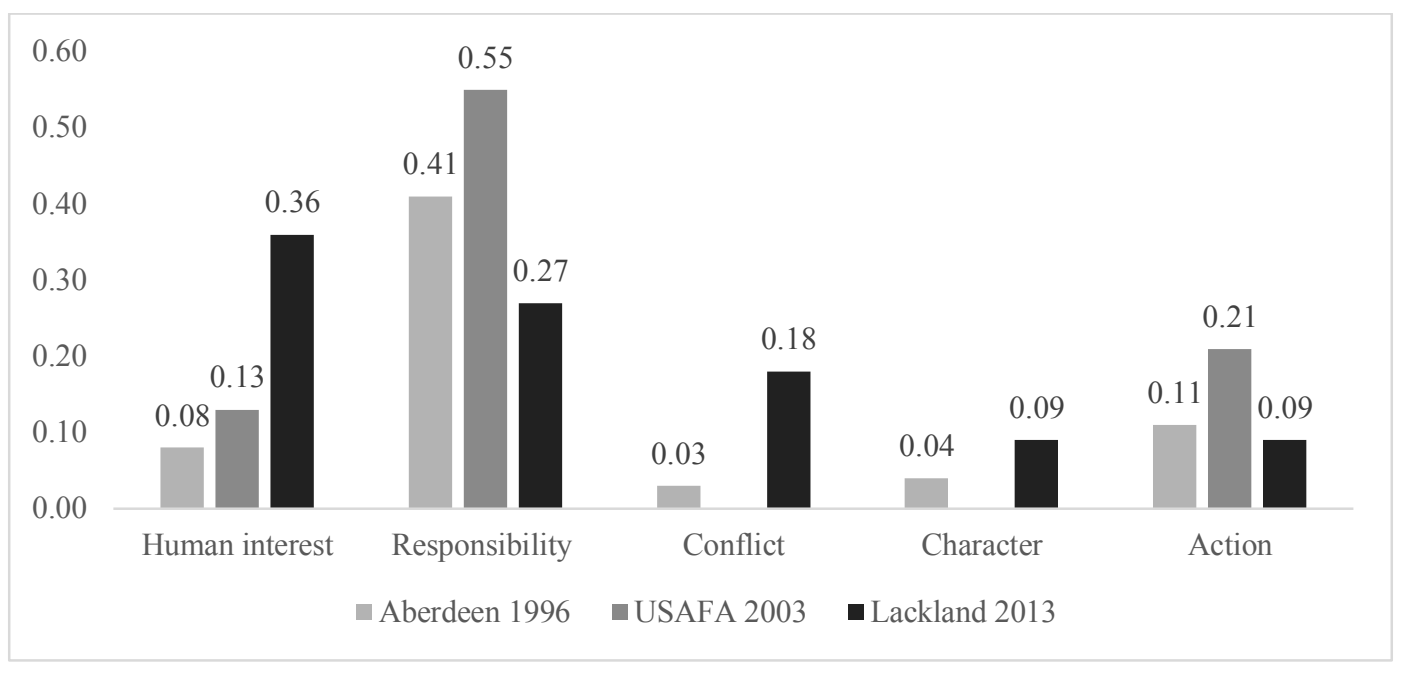

Figure 1. Frequency of Frames.

Research Question 2: Did the media coverage of sexual assault in the military change over time? As indicated in Figure 2, the number of articles written per military sexual assault scandal decrease over time. In 1996, 74 articles were written about the Aberdeen Proving Grounds sexual assault scandal. In 2003, when the United States Air Force Academy sexual assault scandal was publicized, the number of articles written about it by the identified newspaper outlets was 48. Finally, in 2013, when the Lackland Air Force Base sexual assault scandal was made public, the number of articles written about it by the identified newspaper outlets was 11 .

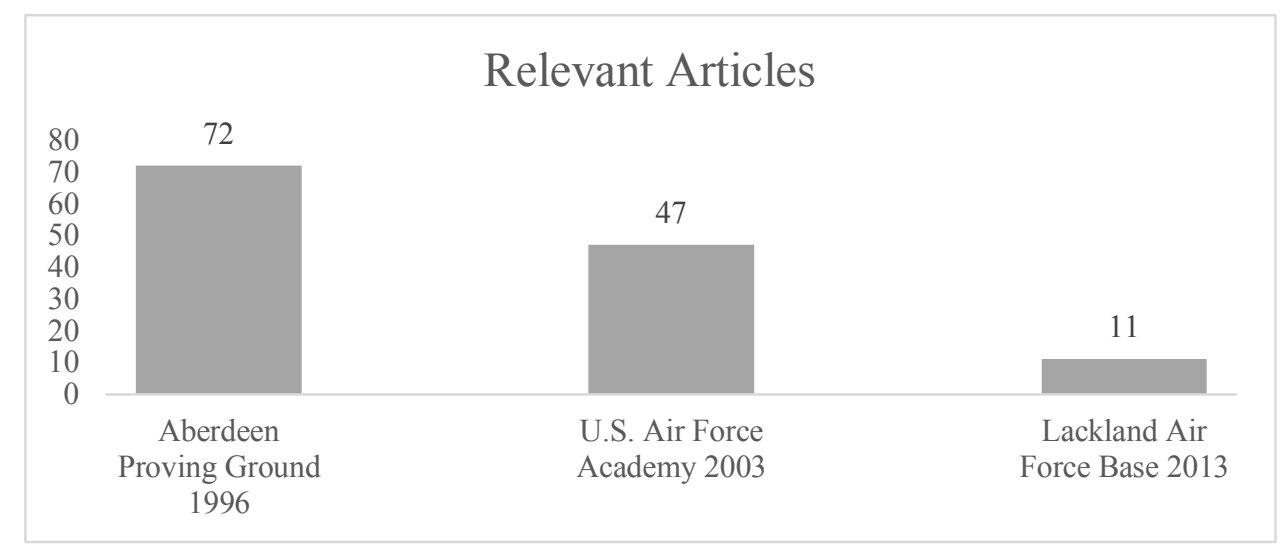

Figure 2. Articles over Time.

\subsection{Discussion}

The first research question was which frames frequently used by the media are most prominent in reports of military sexual violence. Print news media direct the attention of the readers to issues through articles. These articles are written to elicit a response from its readers and to keep them coming back to their source for news. Framing stories in a certain way are partly how news outlets do this.

The two predominant frames discovered in this study were responsibility and human-interest. The use of responsibility increases from the first to the second case, and then decreases during the third case. The human-interest frame gradually increases throughout the three cases. This finding is interesting because it shows an increase in the attention paid to the victims, their families, and the community. During the Aberdeen Proving Ground scandal, the U.S. was between the Cold War and the War on Terror, facing the reactions from the Gulf War (Iyengar and Simon 1993; Iyengar 1991). 
This scandal came at a time when the military was also recovering from Tailhook (Kasinsky 1998), and sexual assault in the military was near the top of the list of Armed Forces issues. The articles written during this time did not have much background information, personal information, or offer some type of vignette to allow readers to make an empathetic or sympathetic connection with people in the news stories. The readers were left with a majority of articles containing the responsibility frame. The media were focused on giving the people someone or something to blame.

Aberdeen Proving Ground Sexual Assault Cases. Multiple drill sergeants and commanding officer were responsible for multiple incidents of sexual assault, sexual harassment, and sexual misconduct. The media made an interesting effort in portraying the sexual assault scandal in the responsibility frame to identify who was to be blame for this pervasive issue. Outside organizations, namely the National Association for the Advancement of Colored People (NAACP), got involved and tried to show that the government was responsible through racism and victim blaming (Soldier 1997).

Data suggest that 41.6 percent of the articles written during the Aberdeen Proving Ground scandal contained the responsibility frame. The newspaper's writers may have felt that this was a strong way in which to convey the information. In addition, that it could have been the best frame at the time to get the public's attention. The news media has been accused of being responsible for guiding public perception to believe who or what is the cause of key social problems (Semetko and Valkenburg 2000). In this instance, military sexual assault is the social problem the media are searching for someone to blame.

The articles show that the news media were on blaming three separate entities. The first group identified are the leaders of the military unit that trains the new recruits. These leaders targeted the new recruits using status and power to order them to do what they wanted. One news story includes graphic testimony from the courts-martial of Staff Sergeant Delmar Simpson (Soldier 1997). The story describes how a young female soldier testified in court that her drill sergeant raped her and then threatened to kill her if she ever told anyone what happened. By identifying the perpetrators in the news articles, it gave their readers the idea to blame those accused of this crime.

Kilborn (Sex Charges 1997) wrote about how one of the victims, Private Brandi Krewson, was quoted, "I agreed to tell them what they wanted to hear in order for them to leave me alone", (Sex Charges 1997, p. 14). Another victim, Kathryn Leming, said, "I never admitted that I was raped. They pushed me and pushed me until basically they tried to make me say 'rape', but I would not do it. It was not the truth" (Sex Charges 1997, p. 14). Sciolino (Sergeant 1997) quoted Janice Grant, who was a local leader of the NAACP in Maryland, as saying, "I believe this verdict is an attack on the leadership of the African-American male, I do not believe that he should be convicted of even one rape" (Sergeant 1997, p. 69). The NAACP believed that the military investigators and Army senior leaders pushed the white victims to lie about the rapes. This quote and the other news stories written about the perceived racism and inappropriate actions of Army investigators surrounding this scandal were framed to influence the public to blame the government for the scandal.

The third group blamed by the media were the victims themselves. Many of the news articles covered the victims' role in the sexual assaults. There were witnesses who were acquaintances of the victims who testified that they were conducting themselves inappropriately and thus making them targets. Lewis (Sergeant's Lawyers 1997) wrote about how lawyers blamed the victims as being "habitual liars who openly yearned to have intimate relations" (Sergeant's Lawyers 1997, p. 12) with Staff Sergeant Simpson. One witness testified that one of the victims would walk by Staff Sergeant Simpson's office in skimpy clothing to get his attention because she wanted to make him a sexual conquest (Sergeant's Lawyers 1997). Sciolino (Sergeant 1997) called the victims "vindictive seductresses" in her article about the court proceedings of Staff Sergeant Simpson. These articles clearly illustrate the pitfalls of victim blaming. Victim blaming is a large part of rape culture and is to be present in this scandal. Many of the young female victims had their ideas about rape distorted by lawyers and members of outside organizations such as the NAACP. 
The scandal facilitated the Army's re-examination of their policies that were in place that covered sexual assault and sexual harassment. The media framing identified those responsible for the scandal and the Army's reaction to this coverage. The Army identified a problem within its ranks through the exposure of the Aberdeen Proving Ground scandal. They reviewed training and steps taken to prevent sexual violence. The Army also explored how to change the command climate that soldiers worked in for the better, and how to eliminate sexual harassment from the ranks (Rosen and Martin 1998).

The focus on the responsibility frame seemed to impact the changes the Army made, because the organization was one of the targets of the media. There was no formal accountability of sexual harassment cases in the mid-to-late-20th century. Prior to 1989, the different military services were not required to compile any type of statistics on sexual misconduct (Wilds 1999). This aspect was a large contributing piece of the rape culture. The use of the responsibility frame, changed slightly with the dawning of another sexual assault scandal. This time the scandal was at the U.S. Air Force Academy, when claims that reports of sexual assault had been uninvestigated and unprosecuted appeared on the desk of Senator Wayne Allard of Colorado.

United States Air Force Academy Sexual Assault Cases. During this scandal, these data reveal two interesting findings. First, the responsibility frame usage increased by almost 14 percent from the Aberdeen Proving Ground scandal. Second, the human-interest frame usage increased over four percent. During this time, the war in Iraq was beginning to gain steam, and the media's focus was war stories. They took different approaches to the war in Iraq, the war in Afghanistan, and the fight against terrorism (Ryan 2004). The news media seemed to be influencing people to form empathetic or sympathetic connection with those identified as victims, and then increasing the responsibility frame to blame those identified as perpetrators. This framing approach emphasizes emotion and blaming and it seemed to have an influence on the optics of the sexual assault scandal at the Academy.

The results show that the frame most used, by the news media studied, was the responsibility frame. This sexual assault scandal was especially egregious because not only was it a military setting but it was a college style setting as well. The victims were students, both college and high school levels, and the leadership at the Academy was responsible for their protection. The news media drove this point in many of the articles in an attempt to show the depth of the problem. This was seen in the way that the leadership and the perpetrators were portrayed in the articles through the responsibility frame. The inquiry, along with the help of the media, exposed many leaders as being harsh, uncaring, and unconcerned about the probe and prosecution of sexual assault.

The news media reported that many of the senior leaders at the Air Force Academy used victim blaming when it came to the majority of the reports of sexual assault. Young female cadets were told that they should not have been drinking at the unauthorized parties they attended. They were told that they should not be hanging out in the males' dorm rooms. Multiple minor offenses were used against them when they reported sexual assault. Many victims of sexual assault did not come forward due to fear of being punished for minor infractions. These issues are found in rape culture and the media exposes them in their articles (Soldier 1997). It should also be noted that the Lackland Scandal produced the least amount of news coverage and, therefore, results should be interpreted with caution.

This scandal revolved around serious abuses of power. Many of the cadets who committed the sexual assaults were using their rank, privilege, and many times alcohol, to force themselves on young female cadets. The female cadets were so afraid of the power that the upperclassmen had and the influence of senior leadership, that they did not tell their closest friends or family what happened to them for a long time (Janofsky and Schemo 2003). These interviews showed how the media were increasing their use of the human-interest frame during the revelation of the scandal in order to draw out emotions in their readers.

The rape culture, which was identified by the news media through the exposure of victim blaming that was used by the senior leadership, was present within the Air Force Academy. It was enforced through the protection of the perpetrators by placing the incident back on the victim and even discharging some of the victims from the military because they were raped. The news media 
identified one leader, Colonel Laurie Slavec, as the officer in charge of cadet conduct and discipline. It was noted in a report from the Pentagon as stating that she did not know what the Air Force's official definition of rape. She discussed with military officials that she had never seen a case of "true rape" among cadets (Schemo 2003a). Colonel Slavec referred to the commonly held rape myth that the only true form of sexual assault is the man who hides in wait for a woman, beats her senseless and violently rapes her (Krakauer 2015).

Brigadier General S. Taco Gilbert III, the Commandant of Cadets, was also one of the leaders who supported the rape culture. According to Gilbert, cadets who reported sexual assault were punished for any and all infractions, and forcefully insisted that they brought on the sexual assault themselves because of their drinking and partying (Schemo 2003b). This stance made it unlikely that those assaulted would report it to leadership. The fact that many victims faced reprisal and punishment from not only their leadership but from fellow cadets, was one of the main reasons victims sought out the help of Senator Wayne Allard of Colorado. This demonstrates that there was a pervasive rape culture within the masculine dominated organization of the military.

Lackland Air Force Base Sexual Assault Cases. During news media coverage of this scandal, there were two drastic changes in media framing. The use of the human-interest frame increased by 24 percent and the use of the responsibility frame decreased by 28 percent. These changes could indicate that the human-interest frame was proving to be more useful than the responsibility frame. During 2013, the U.S. was facing issues that were controversial: the Edward Snowden leak of classified material, the Bradly Manning court hearings, states' legalization of marijuana and interests in Iraq and Afghanistan had decreased (Great Stories 2013). It seemed that the media were focusing on increasing the human connection between the readers and the victims. This suggests that the public was increasing their interest in the people involved in issues reported by the media rather than focusing on who or what was responsible for the issue. As noted previously, the Lackland Air Force case produced far fewer news stories and any findings should be interpreted with caution.

The frame most used during this scandal was the human-interest frame. In this situation, which was very similar to the Aberdeen Proving Ground scandal, the drill instructors were preying on young recruits that were coming to them for training. The Air Force instructors have such power over the recruits that many of them will do almost anything ordered by senior ranking personnel. This framework, in which the news media presented their stories about this scandal, seems to guide readers to how vulnerable the trainees were to these misogynistic men who took advantage of their power and position. Jervis (Scandal 2012) used the words "Shock. Anger. Disgust. Disbelief" (Scandal 2012, p. 3) to describe reactions to the scandal that involved over two dozen Air Force training instructors. These words almost immediately draw those types of feelings out of the reader especially when paired with the crime committed and the victims' personal experiences.

The framing of the articles indicated that there were parts of rape culture that existed in these scandals demonstrated by the thoughts and reactions of the victims. Many of the victims did not report the sexual assaults because they felt that if they told authorities what happened, they would be the ones who would be punished (Dao 2012). One victim testified at Staff Sergeant Walker's trial saying, "I was scared. What if he punished me or ruined my career?" when she was asked about why she did not report the sexual assault right away (Dao 2012, p. 22). This comment, and many other statements about how the victims thought and felt, shows how rape culture influences people into believing that they will be punished for being sexually assaulted. Fear of reprisal is one of the main reasons listed by many victims as to why they did not report the sexual assaults immediately. This demonstrates how prominent victim blaming and rape culture is in many cultures and was identified by the media through the frames used within these news stories.

The second question was, has the coverage of military sexual assaults changed over time? After the news articles were pulled from the Lexis Nexis database, they were reviewed for relevancy. Once relevancy was established, they were counted and the result shows that the number of news articles covering the different sexual assault scandals actually decreased considerably over time. 
There is initiative from the military to publicly discipline those service members who commit sexual assault and the senior military leaders linked to these scandals. This suggests that the military wants the public to see that they are doing something about the problem. The news media, however, do not seem to show the same sentiment. How news media shape public perception of these actions in attempt to elect some type of reaction would suggest they feel that the quality of their work over time gets the message through rather than quantity. The public could have also lost interest or have become accustomed to stories of sexual violence, therefore see it as less of an issue. As noted previously, the Lackland Air Force case produced far fewer news stories and any findings should be interpreted with caution.

The public could also have been distracted by many of the issues that were going on at the same time as described earlier in this section. The issue of sexual assault could have been viewed as a distraction from some of the other issues that were going on in the U.S., or contrary to that, the other issues could have been a distraction from the continuous issue of sexual assault in the military.

Many women feared that their chain of command would not believe them or think that they were being over sensitive even if they did report sexual assault (Wilds 1999). Weakness in the eyes of their male superior officers was also a fear. Official policy stated that incidents of sexual misconduct were to be handled at the lowest level possible before advancing to senior leadership. If the victims failed to adhere to this policy they were viewed as weak. Many were also afraid that if they did not handle it at their level, they would fall prey to further victim blaming and face retaliation of some sort from their command (Wilds 1999).

The military is a male dominated culture by sheer numbers alone. It is a subculture that is based on a cultural identity that revolves around masculinity as a measure of how one performs. There is the possibility that because the consistent attention regarding sexual assault is so frequent, that the public has begun to accept that sexual violence in the military is something that just happens and not what drives the sale of newspapers. Conversely, there is the possibility that because there have been so many military sexual assaults scandals, the public may not want to read about it any longer due to the view that the problem is not being solved no matter how much attention it gets. News media outlets are a business. They frame and print stories that they believe sell newspapers. This is based on what news outlets believe the public wants to read about.

The frames discovered in the news articles indicate issues of sexual assault that is embedded within the military. The military culture is influenced by the different types of media and social schemas that influence people into believing that, to be in the military, one must be brave, aggressive, strong, and capable of defeating the enemies of the United States. These social schemas support that showing weakness or empathy is wrong in the military and could get service members killed. These ideas are what many people attracted to the military are raised with and once in the service their ideas spread because of the common acceptance of aggressiveness, violence, strength, and bravery that are tied to masculinity. The dark side of these traits are seen through some of the frames used by the media when reporting military sexual assault. Organizational Culture theory and Masculinities theory are useful when examining how the news media frames the military sexual assault cases. These theories assist in having a better understanding of the hyper-masculine, organizational culture of the military. Media framing of the military has an impact on these thoughts, ideas, and actions by writing articles about the military that makes the issues salient to the reader.

\subsection{Limitations}

This study used two newspaper outlets that were in the top five in the country that wrote articles on the studied cases. The goal was to see how the media was framing their stories about the military during times of sexual assault scandal. The New York Times and USA Today were shown as reaching the most people, according to distribution numbers, and were then determined to be the most read and most influential. This study did not use any other news media outlets and therefore the findings are limited to the data pulled. 
Only using two news media outlets can impair results by only identifying the frames that are used by those two outlets. There may be other frames in which different news media outlets may use that are not identified in this research. The limited number of authors may skew the results toward a frame in which they are comfortable writing in or that they are bias toward. Kuypers (2002) discussed how the facts of news stories are just that and stay that way until authors frame them and make some parts more salient than others. This bias in framing may be more difficult to identify in the use of limited authors and could be a misrepresentation of the actual common frames used by the press. However, the news media outlets identified are two of the predominant ones listed by the PEW research center (News Media 2017), and reach many people within the United States. They also include articles that are identified as written by the Associated Press, which could work toward minimizing the bias.

This study was primarily focused on the media coverage of females as victims and does not go into the numbers of males that are victims of sexual assault within the military. The sexual assault issues that are outside the scope of the three scandals studied may contain cases where men are victims. The coverage of other military sexual assault cases could offer a different perspective of sexual assault that researchers could study to identify trends and instances that contribute to this social phenomenon. It can offer a wider scope of study in understanding media framing of sexual assault issues in the military. Studying how media frames military sexual assault could be enhanced through widening the research to other cases.

\section{Conclusions and Recommendations for Future Research}

\subsection{Conclusions}

This study examined how two major news outlets framed sexual assault in the military in their coverage of the incidents and the number of news stories written about each of the scandals. Analysis also included exploring how coverage of military sexual assaults changed over time. It was discovered that news articles about sexual assault in the military decreased over time since the mid-1990s. This was evident from the decrease in news coverage the military sexual assault scandals received.

How the news media frames their stories is important because they can help identify issues that can shape changes in society. Articles are written in a manner to elicit a certain response from the public. The public should be aware that the news media conducts such framing (Graber 1993; Bennett 1995). The public response to what they read and how they feel, can drive change in the hyper-masculine sub-culture of the military. The media identified through the action frame that there were organizational changes made, and that still needed to be made to transform the misogynistic aspect of the military and prevent sexual assault.

These data showed the responsibility frame with a high percentage of use which indicates that whoever is to blame, or who is held responsible, needs to change. It also demonstrates an increase in the human-interest frame which indicates that more attention should be focused on the victim-centered approach to sexual assault. The conflict frame showed an increase in use, along with the character frame, which illustrates a focus on the conflict between the victims and their leadership, the leadership and the perpetrators, and the victims and their perpetrators.

Effective leadership can identify these frames and gain an idea of how the media is portraying the sexual assault issue within the military. This type of leadership seems to be what media is showing as what the military requires to change the underlying beliefs of the culture that is permissive of sexual assault. The military has a high level of control over its service members due to the Uniform Code of Military Justice, however, it cannot regulate their hearts and minds which are highly influenced by civilian culture prior to enlisting. However, the military can impact attitudes about sexual misconduct and demonstrate that this type of violence is incompatible with the views and values of service.

Media frames are used to convey information to people which influences how they think, act, and feel. Military and government leaders can use this information to focus on culture change instead of just repressing behaviors (Schein 2010). Repression is a theme that shines through in articles written 
about military sexual assault. If the human-interest frame is as strong as those found in this study, then all service members should take it upon themselves to change the culture that is permissive of sexual misconduct. This change can be a framing effect that could lead to fewer sexual assault cases. The public can be engaged to help transform the culture by promoting social change (Schein 1990).

\subsection{Recommendations for Future Research}

Many aspects of this study could be expanded on. For future studies of this type, more news media outlets should be used. Studying more news media outlets can provide researchers with a clearer idea of how the military sexual assault scandals are framed from a larger perspective. Future studies in this area should attempt to include other forms of news media such as television, radio, and Internet. Another aspect of this subject that can be studied is the public opinion of the news media outlets, through surveys and interviews. This could allow for the ability to see how the public perceives the frames that the news media use to present stories.

In regards to military sexual assault, much remains unknown (Sexual Assault in the Military 2013). This paper attempted to bring more awareness to how the media frames the crime of sexual assault in the military. One thing that researchers struggle with is why the media uses certain frames when reporting sexual assault in the military. A possibility could be that it comes in the form of culture, because principles underwrite our behaviors, influences writers when presenting stories, and are influenced by the stories we see and read. Impacts on Organizational Cultural change by the news media should be studied more in the future.

Framing effects can influence public opinion. While that is beyond the scope of this study, it is clear that the media used three predominant frames during these scandals. The effects of the media framing are shown to have an impact on social and cultural change (Semetko and Valkenburg 2000). Semetko and Valkenburg (2000) found that frames shape public perceptions of political issues or institutions. They identified experiments with question wording on surveys where they learned that perception can be swayed in different directions according to how the problems are presented in questions. Public opinion of sexual assault in the military, because of media framing, should be researched to help understand why the media uses specific frames and how they may increase public awareness further, and work to elicit social and cultural change.

Finally, new laws, training and education programs have been implemented since the last sexual assault scandal covered in the study. In 2011, the Navy started implementing bystander intervention training and every branch adopted the same prevention tactic soon afterward (Defense Annual Report 2011, p. 6). The bystander intervention prevention method encourages military members to intervene if they witness another service member being targeted in a violent or sexual way. Through a 2012 department of Defense (DoD) survey after the training, the majority of all service members believed the training provided practical skills in which they could use to address instances of sexual violence (Defense Annual Report 2011, p. 12).

The military introduced another form of sexual assault prevention that addresses leadership's role in creating a climate in which violence is not tolerated. Legislation passed in 2013 now requires specific mandatory Sexual Assault Prevention and Response (SAPR) training for commanders at all levels that aims to resolve and respond to sexual violence that occurs within their units. This training provides best practices when dealing with instances of sexual assault, as well as addresses the needs of victims, and the rights of the accused. Along with this legislation, it is now required that unit climate assessments are given annually as a way to support commander's efforts in dealing with the improvement of prevention strategies and response actions (Defense Annual Report 2011, p. 13).

Based on information draw from the 2016 Department of Defense Annual Report on Sexual Assault in the Military, these and other interventions have been effective in reducing the prevalence of sexual assault and harassment, as well as increasing the number military members coming forward to report these violent incidences. In 2016, 4.3 percent of active duty women and 0.6 percent of active duty men reported experiencing a sexual assault in the year prior, which is a significant reduction 
of occurrence from 2014 (Defense Annual Report 2016, p. 9). This report highlights that, in 2014, the DoD estimated that there were nearly 20,000 sexual assault victims, 23 percent of which reported the incident, while in 2016, the DoD estimated there were slightly fewer than 15,000 victims, with a 32 percent reporting rate (Defense Annual Report 2016, p. 12). The initiatives the DoD has taken seem to be pushing the military in the right direction in creating an environment in which sexual violence no longer exists.

These intervention efforts appear to be having an impact on the number of sexual assaults and may also shape public narratives about the issue in the military. The impact of military policy and procedure changes in the wake of large scale sexual assault scandals deserves investigation. Specifically, researchers should engage policy makers in understanding the nexus between troubling events, media coverage and organizational change. These lines of inquiry will provide valuable insight into how the military responds to internal and external pressure to address sexual violence in the Armed Forces.

Author Contributions: S.K. is the main author of the paper with assistance from A.M. Analyses were conducted by A.E.K. and S.B.R.

Conflicts of Interest: The authors declare no conflict of interest.

\section{References}

Anderson, Craig A., and Brad J. Bushman. 2000. The effects of media violence on society. Science 395: $2377-79$. Available online: http:/ / science.sciencemag.org/content/295/5564/2377.full (accessed on 14 November 2017). [CrossRef]

Bennett, W. Lance. 1995. News: The Politics of Illusion. New York: Longman, ISBN: 978-0226340524.

Bing, Janet M., and Lucien X. Lombardo. 1997. Talking past each other about sexual harassment: An exploration of frames for understanding. Discourse $\mathcal{E}$ Society 8: 293-311. [CrossRef]

Capella, Michael L., Ronald Paul Hill, Justine M. Rapp, and Jeremy Kees. 2013. The impact of violence against women in advertisements. Journal of Advertising 39: 37-52. [CrossRef]

Carlsson, Christoffer. 2013. Masculinities, persistence, and desistance. Criminology 51: 661-93. Available online: http:/ / onlinelibrary.wiley.com/doi/10.1111/1745-9125.12016/full (accessed on 16 November 2017). [CrossRef]

Castro, Carl Andrew, Sara Kintzle, Ashley C. Schuyler, Carrie L. Lucas, and Christopher H. Warner. 2015. Sexual assault in the military. Current Psychiatry Reports 17: 1-13. Available online: https://link.springer.com/ article/10.1007/s11920-015-0596-7 (accessed on 13 November 2017). [CrossRef] [PubMed]

Cheney, Ann M., Heather Schact Reisinger, Brenda M. Booth, Michelle A. Mengeling, James C. Torner, and Anne G. Sadler. 2014. Servicewomen's Strategies to Staying Safe during Military Service. New York: Springer Science + Business Media, ISBN: 1098-092X.

Chesebro, James W. 1984. The media reality: Epistemological functions of media in cultural systems. Critical Studies in Mass Communication 1: 111-30. Available online: http:/ /www.tandfonline.com/doi/abs/10.1080/ 15295038409360024 (accessed on 14 November 2017). [CrossRef]

Cohen, Jacob. 1960. A coefficient of agreement for nominal scales. Educational and Psychological Measurement 23: 37-40. Available online: http:/ / www.garfield.library.upenn.edu/classics1986/A1986AXF2600001.pdf (accessed on 17 November 2017). [CrossRef]

Dalton, Colleen. 2004. The sexual assault crisis in the United States air force academy. Cardozo Women's Law Journal 11: 177-90. Available online: http://heinonline.org/HOL/LandingPage?handle=hein.journals/cardw11\& $\operatorname{div}=13 \&$ id $=$ \&page $=($ accessed on 17 November 2017) .

Dao, James. 2012. Instructor for Air Force is convicted in sex assaults. The New York Times, July 21. Available online: http:/ / www.nytimes.com/2012/07/21/us/lackland-air-force-base-instructor-guilty-ofsex-assaults.html (accessed on 17 November 2017).

Dean, Donna Margaret. 1994. Warriors without Weapons: The Victimization of Military Women. Pasadena: Minerva Center, pp. 1352-62, ISBN: 978-0963489531.

Defense Annual Report. 2011. Department of Defense Annual Report on Sexual Assault in the Military Fiscal Year 2011. Available online: http://www.sapr.mil/public/docs/reports/Department_of_Defense_Fiscal_Year_ 2011_Annual_Report_on_Sexual_Assault_in_the_Military.pdf (accessed on 13 April 2018). 
Defense Annual Report. 2016. Department of Defense Annual Report on Sexual Assault in the Military Fiscal Year 2016. Available online: http://www.sapr.mil/public/docs/reports/FY16_Annual/FY16_SAPRO_Annual_ Report.pdf (accessed on 12 April 2018).

Denison, Daniel R., and Aneil K. Mishra. 1995. Toward a theory of organizational culture and effectiveness. Organization Science 1: 204-23. Available online: http://journals.sagepub.com/doi/pdf/10.1177/ 1534484309333619 (accessed on 16 November 2017). [CrossRef]

Entman, Robert M. 1993. Framing: Toward clarification of a fractured paradigm. Journal of Communication 43: 51-58. [CrossRef]

Esterberg, Kristin G. 2002. Qualitative Methods in Social Research. New York: McGraw-Hill Education, ISBN: 978-0767415606.

Flick, Uwe. 2014. Qualitative content analysis. In The SAGE Handbook of Qualitative Data Analysis. London: SAGE Publications Ltd., pp. 170-83, ISBN: 978-1446208984.

Fowler, Tillie K. 2003. Report of the Panel to Review Sexual Misconduct Allegations at the U.S. Air Force Academy. Washington: Department of Defense Publishing Office.

Franiuk, Renae, Jennifer L. Seefelt, and Joseph A. Vandello. 2008. Prevalence of rape myths in headlines and their effects on attitudes toward rape. Sex Roles 58: 790-801. [CrossRef]

Graber, Doris. 1993. Mass Media and American Politics. Washington: CQ Press, ISBN: 978-1452287287.

Great Stories. 2013. A Year in Review: Great Stories of 2013. Available online: http:/ /www.washingtonpost.com/ sf/style/collection/the-best-of-2013/?utm_term=.4da6377ff1b4 (accessed on 17 November 2017).

Holland, Kathryn J., Verónica Caridad Rabelo, and Lilia M. Cortina. 2014. Sexual assault training in the military: Evaluating efforts to end the "Invisible War". American Journal of Community Psychology 54: 289-303. Available online: http:/ / onlinelibrary.wiley.com/doi/10.1007/s10464-014-9672-0/full (accessed on 14 November 2017).

Hsieh, Hsiu-Fang, and Sarah E. Shannon. 2005. Three approaches to qualitative content analysis. Qualitative Health Research 15: 1277-88. [CrossRef]

Iyengar, Shanto. 1987. Television news and citizens' explanations of national affairs. American Political Science Review 81: 815-31. Available online: http:/ / www.jstor.org/stable/1962678?origin=crossref\&seq=1\#page_ scan_tab_contents (accessed on 16 November 2017).

Iyengar, Shanto. 1991. Is Anyone Responsible?: How Television Frames Political Issues. Chicago: University of Chicago Press, ISBN: 978-0226388557.

Iyengar, Shanto, and Adam Simon. 1993. News coverage of the Gulf crisis and public opinion: A study of agenda-setting, priming, and framing. Communication Research 15: 1277-88. [CrossRef]

Janofsky, Michael, and Diana Jean Schemo. 2003. Women recount life as cadets: Forced sex, fear and silent rage. The New York Times, March 16. Available online: http:/ /www.nytimes.com/2003/03/16/us/womenrecount-life-as-cadets-forced-sex-fear-and-silent-rage.html (accessed on 17 November 2017).

Jozkowski, Kristen N. 2015. Beyond the Dyad: An assessment of sexual assault prevention education focused on social determinants of sexual assault among college students. Violence against Women 21: 848-74. Available online: http:/ /journals.sagepub.com/doi/pdf/10.1177/1077801215584069 (accessed on 13 November 2017). [CrossRef] [PubMed]

Kasinsky, Renee Goldsmith. 1998. Tailhook and the construction of sexual harassment in the media. Violence Against Women 4: 81-99. [CrossRef]

Katz, Jackson. 1995. Reconstructing masculinity in the locker room: The mentors in violence prevention project. Harvard Educational Review 65: 163-74. [CrossRef]

Kohlbacher, Florian. 2006. The use of qualitative content analysis in case study research. Forum: Qualitative Social Research 7: 1-30. Available online: http:/ / www.qualitative-research.net/index.php/fqs/article/view/75/ 153 (accessed on 17 November 2017).

Krakauer, Jon. 2015. Missoula: Rape and the Justice System in a College Town. New York: Doubleday, ISBN: 0385538731.

Kuypers, Jim A. 2002. Press Bias and Politics: How the Media Frame Controversial Issues. Westport and Santa Barbara: Praeger Publishers, ISBN: 978-0275977597.

Lohman, Alexandra. 2015. Silence of the lambs: Giving voice to the problem of rape and sexual assault in the United States armed forces. Northwestern Journal of Law and Social Policy 10: 230-79. Available online: http:/ / scholarlycommons.law.northwestern.edu/cgi/viewcontent.cgi?article=1124\&context=njlsp (accessed on 16 November 2017). 
Matthes, Jörg, and Matthias Kohring. 2008. The content analysis of media frames: Toward improving reliability and validity. Journal of Communication 58: 258-79. [CrossRef]

McKeon, Howard Buck. 2013. A Review of Sexual Misconduct by Basic Training Instructors at Lackland Air Force Base. Washington: United States Government Printing Office.

Messerschmidt, James W. 1993. Masculinities and Crime: Critique and Reconceptualization of Theory. Lanham: Rowman \& Littlefield Publishers, Inc., ISBN: 978-0847678693.

Neill, Kevin Gerard. 2000. Duty, honor, rape: Sexual assault against women during war. Journal of International Women's Studies 2: 43-51. Available online: http://vc.bridgew.edu/cgi/viewcontent.cgi?article=1642\& context=jiws (accessed on 16 November 2017).

Neuman, W. Russell, Marion R. Just, and Ann N. Crigler. 1992. Common Knowledge. Chicago: University of Chicago Press, ISBN: 978-0226574400.

News Media. 2017. The State of the News Media. Available online: http:/ /www.stateofthemedia.org (accessed on 20 March 2017).

Nicoletti, John, Christopher M. Bollinger, and Sally Spencer-Thomas. 2009. Violence Goes to College: The Authoritative Guide to Prevention and Intervention, 2nd ed. Springfield: Charles C. Thomas, Ltd., ISBN: 978-0-3980-7909-3.

Polk, Steven. 2004. Report to the SECAF: Air Force Inspector General Summary Report Concerning the Handling of Sexual Assault Cases at the United States Air Force Academy. Washington: USAF Office of the Inspector General.

Rosen, Leora N., and Lee Martin. 1998. Predictors of tolerance of sexual harassment among male U.S. Army Soldiers. Violence against Women 4: 491-504. Available online: http:/ /journals.sagepub.com/doi/pdf/10. $1177 / 1077801298004004006$ (accessed on 14 November 2017). [CrossRef]

Ryan, Michael. 2004. Framing the war against terrorism: US newspaper editorials and military action in afghanistan. Journal for Communication Studies 66: 363-82. [CrossRef]

Scandal. 2012. Scandal Casts a Pall at Air Force Base in Texas; Claims at Lackland Include Inappropriate Posts, Rapes. Available online: http://www.pressreader.com/usa/usa-today-us-edition/20120720/281513633273572 (accessed on 17 November 2017).

Schein, Edgar H. 1990. Organizational cultur. American Psychologist 45: 109-19. Available online: http:/ / psycnet. apa.org/fulltext/1990-15978-001.html (accessed on 16 November 2017). [CrossRef]

Schein, Edgar H. 2010. Organizational Culture and Leadership, 4th ed. San Francisco: John Wiley \& Sons, ISBN: 978-0-470-18586-5.

Schemo, Diana Jean. 2003a. Air Force ignored sex abuse at academy, inquiry reports. The New York Times, September 23. Available online: http:/ / www.nytimes.com/2003/09/23/us/air-force-ignored-sex-abuse-atacademy-inquiry-reports.html (accessed on 17 November 2017).

Schemo, James. 2003b. Air Force Secretary says academy's leaders could be punished in rape scandal. The New York Times, April 2. Available online: http:/ / www.nytimes.com/2003/04/02/us/air-force-secretary-saysacademy-s-leaders-could-be-punished-in-rape-scandal.html (accessed on 17 November 2017).

Semetko, Holli A., and Patti M. Valkenburg. 2000. Framing european politics: A content analysis of press and television news. Journal of Communication, 93-109. [CrossRef]

Sergeant. 1997. Sergeant Convicted of 18 Counts of Raping Female Subordinates. Available online: http:/ / www. nytimes.com/1997/04/30/us/sergeant-convicted-of-18-counts-of-raping-female-subordinates.html (accessed on 17 November 2017).

Sergeant's Lawyers. 1997. Sergeant's Lawyers Start Case by Accusing 2 of His Accuser. Available online: http:/ / www. nytimes.com/1997/04/22/us/sergeant-s-lawyers-start-case-by-accusing-2-of-his-accusers.html (accessed on 17 November 2017).

Sex Charges. 1997. 5 Women Say Sex Charges in Army Case Were Coerced. Available online: http://www. nytimes.com/1997/03/12/us/5-women-say-sex-charges-in-army-case-were-coerced.html (accessed on 17 November 2017).

Sexual Assault in the Military. 2013. U.S. Commission on Civil Rights 2013 Statutory Enforcement Report. Available online: http:/ /www.usccr.gov/pubs/09242013_Statutory_Enforcement_Report_Sexual_Assault_ in_the_Military.pdf (accessed on 12 April 2018).

Sexual Violence. 2017. Sexual Violence in the Military: A Guide for Civilian Advocates. Available online: http:/ / www.nsvrc.org/sites/default/files / publications_nsvrc_guides_sexual-violence-in-the-military-aguide-for-civilian-advocates.pdf (accessed on 17 November 2017). 
Simons, Ronald L., and Callie Harbin Burt. 2011. Learning to be bad: Adverse social conditions, social schemas, and crime. Criminology 49: 553-98. [CrossRef] [PubMed]

Soldier. 1997. Soldier Tells about Threat after Rape. Available online: http:/ /www.nytimes.com/1997/04/18/us / soldier-tells-about-threat-after-rape.html (accessed on 17 November 2017).

Taylor, Bryan C., Lisa R. Irvin, and Stacey M. Wieland. 2006. Checking the map: Critiquing Joanne Martin's metatheory of organizational culture and its uses in communication research. Communication Theory 16: 304-32. [CrossRef]

USA Today. 2017. Marine Nude Photos a Leadership Disaster: Tailhook Whistle-Blower. Available online: http:/ / www.usatoday.com/story/opinion/2017/03/09/military-failing-women-decades-paulacoughlin-column/98909892/ (accessed on 9 March 2017).

Weitz, Rose. 2015. Vulnerable warriors: Military women, military culture, and fear of rape. Gender Issues 32: 164-83. Available online: https:/ /link.springer.com/article/10.1007\%2Fs12147-015-9137-2 (accessed on 16 November 2017). [CrossRef]

West, Togo. 1997. Secretary of the Army's Senior Review Panel Report on Sexual Harassment. Washington: Department of Defense.

Wilds, Nancy G. 1999. Sexual Harassment in the Military. Pasadena: Minerva Center, Inc.

Zaleski, Kristen. 2016. Understanding and Treating Military Sexual Trauma. New York: Springer International Publishing, ISBN: 2195-2264.

Zaleski, Kristen L., Kristin K. Gundersen, Jessica Baes, Ely Estupinian, and Alyssa Vergara. 2016. Exploring rape culture in social media forums. Computers in Human Behavior 63: 922-27. Available online: http: / / www.sciencedirect.com/science/article/pii/S0747563216304642?via\%3Dihub (accessed on 14 November 2017). [CrossRef]

(C) 2018 by the authors. Licensee MDPI, Basel, Switzerland. This article is an open access article distributed under the terms and conditions of the Creative Commons Attribution (CC BY) license (http:/ / creativecommons.org/licenses/by/4.0/). 